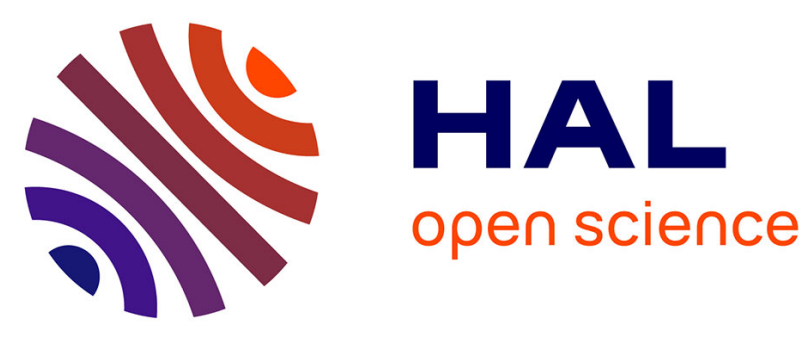

\title{
Heme oxygenase-1 induction modulates microsomal prostaglandin E synthase-1 expression and prostaglandin E production in osteoarthritic chondrocytes
}

Javiermegías, María Isabel Guillén, Victoria Clérigues, Ana I. Rojo, Antonio

Cuadrado, Miguel Angel Castejón, Francisco Gomar, María José Alcaraz

\section{To cite this version:}

Javiermegías, María Isabel Guillén, Victoria Clérigues, Ana I. Rojo, Antonio Cuadrado, et al.. Heme oxygenase-1 induction modulates microsomal prostaglandin E synthase-1 expression and prostaglandin E production in osteoarthritic chondrocytes. Biochemical Pharmacology, 2009, 77 (12), pp.1806. 10.1016/j.bcp.2009.03.009 . hal-00493503

\section{HAL Id: hal-00493503 https://hal.science/hal-00493503}

Submitted on 19 Jun 2010

HAL is a multi-disciplinary open access archive for the deposit and dissemination of scientific research documents, whether they are published or not. The documents may come from teaching and research institutions in France or abroad, or from public or private research centers.
L'archive ouverte pluridisciplinaire HAL, est destinée au dépôt et à la diffusion de documents scientifiques de niveau recherche, publiés ou non, émanant des établissements d'enseignement et de recherche français ou étrangers, des laboratoires publics ou privés. 


\section{Accepted Manuscript}

Title: Heme oxygenase-1 induction modulates microsomal prostaglandin E synthase-1 expression and prostaglandin $\mathrm{E}_{2}$ production in osteoarthritic chondrocytes

Authors: JavierMegías, María Isabel Guillén, Victoria Clérigues, Ana I. Rojo, Antonio Cuadrado, Miguel Angel Castejón, Francisco Gomar, María José Alcaraz

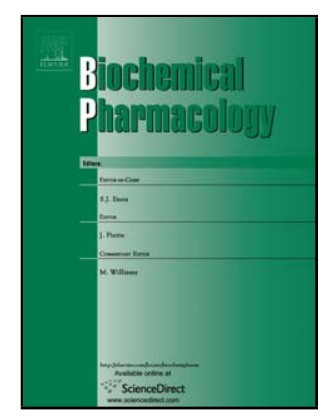

PII: S0006-2952(09)00184-1

DOI: doi:10.1016/j.bcp.2009.03.009

Reference: BCP 10114

To appear in: $\quad B C P$

Received date: $\quad 3-11-2008$

Revised date: $\quad$ 5-3-2009

Accepted date: $\quad$ 6-3-2009

Please cite this article as: JavierMegíasGuillén MI, Clérigues V, Rojo AI, Cuadrado A, Castejón MA, Gomar F, Alcaraz MJ, Heme oxygenase-1 induction modulates microsomal prostaglandin E synthase-1 expression and prostaglandin $\mathrm{E}_{2}$ production in osteoarthritic chondrocytes, Biochemical Pharmacology (2008), doi:10.1016/j.bcp.2009.03.009

This is a PDF file of an unedited manuscript that has been accepted for publication. As a service to our customers we are providing this early version of the manuscript. The manuscript will undergo copyediting, typesetting, and review of the resulting proof before it is published in its final form. Please note that during the production process errors may be discovered which could affect the content, and all legal disclaimers that apply to the journal pertain. 
Heme oxygenase-1 induction modulates microsomal prostaglandin E synthase-1 expression and prostaglandin $\mathbf{E}_{2}$ production in osteoarthritic chondrocytes

JavierMegías $^{\mathrm{a}}$, María Isabel Guillén ${ }^{\mathrm{a}, \mathrm{b}}$, Victoria Clérigues ${ }^{\mathrm{a}}$, Ana I. Rojo ${ }^{\mathrm{c}}$, Antonio Cuadrado $^{\mathrm{c}}$, Miguel Angel Castejón ${ }^{\mathrm{d}}$, Francisco Gomar ${ }^{\mathrm{e}}$ and María José Alcaraz ${ }^{\mathrm{a}, *}$

${ }^{a}$ Department of Pharmacology; Faculty of Pharmacy, University of Valencia, 46100 Burjasot, Spain.

${ }^{b}$ Department of Chemistry, Biochemistry and Molecular Biology, Cardenal HerreraCEU University, 46110 Moncada, Spain.

${ }^{\mathrm{c}}$ Department of Biochemistry and Alberto Sols Institute of Biomedical Investigations, UAM-CSIC, Madrid, Spain.

${ }^{\mathrm{d}}$ Department of Orthopaedic Surgery and Traumatology, Hospital Universitario de la Ribera, 4660, Alzira, Spain.

${ }^{\mathrm{e}}$ Department of Surgery, Faculty of Medicine, University of Valencia, 46010 Valencia, Spain.

Manuscript category: (5) INFLAMMATION AND IMMUNOPHARMACOLOGY

Address correspondence and reprint requests to: Prof. M. J. Alcaraz, Department of Pharmacology, University of Valencia, Faculty of Pharmacy, Av. Vicent Andrés Estellés s/n, 46100 Burjasot, Valencia, Spain. Tel: 34-963544292; Fax: 34-963544499; E-mail: maria.j.alcaraz@uv.es 


\section{ABSTRACT}

Pro-inflammatory cytokines such as interleukin-1 $\beta$ (IL-1 $\beta$ ) may participate in the pathogenesis of cartilage damage in osteoarthritis (OA) through the production of catabolic enzymes and inflammatory mediators. Induction of heme oxygenase-1 (HO-1) has previously been shown to exert anti-inflammatory effects in different cel types. We have investigated whether HO-1 induction may modify chondrocyte viability and the production of relevant mediators such as oxidative stress and prostaglandin $\mathrm{E}_{2}\left(\mathrm{PGE}_{2}\right)$ elicited by IL-1 $\beta$ in OA chondrocytes. Chondrocytes were isolated from OA cartilage and used in primary culture. Cells were stimulated with IL-1 $\beta$ in the absence or presence of the HO-1 inducer cobalt protoporphyrin IX (CoPP). Gene expression was assessed by quantitative real-time PCR, protein levels by ELISA and Western blot, apoptosis by laser scanning cytometry using annexin V-FITC and TUNEL assays, and oxidative stress by LSC with dihydrorhodamine 123 . HO-1 induction by CoPP enhanced chondrocyte viability and aggrecan content while inhibiting apoptosis and oxidative stress generation. $\mathrm{PGE}_{2}$ is produced in $\mathrm{OA}$ chondrocytes stimulated by IL-1 $\beta$ by the coordinated induction of cyclooxygenase- 2 and microsomal PGE synthase 1 (mPGES-1). The production of $\mathrm{PGE}_{2}$ was decreased by HO-1 induction as a result of diminished mPGES-1 protein and mRNA expression. Transfection with HO-1 small interfering RNA counteracted CoPP effects. In addition, the activation of nuclear factor- $\mathrm{\kappa B}$ and early growth response- 1 was significantly reduced by CoPP providing a basis for its anti-inflammatory effects. These results confirm the protective role of HO-1 induction in $\mathrm{OA}$ chondrocytes and suggest the potential interest of this strategy in degenerative joint diseases. 
Key words: Heme oxygenase-1, Chondrocyte, Osteoarthritis, Interleukin-1 $\beta$, Prostaglandin $\mathrm{E}_{2}$, microsomal PGE synthase-1.

Running headline: HO-1 in chondrocytes 


\section{Introduction}

The chronic production of inflammatory mediators by articular tissues is an important feature of rheumatoid arthritis and osteoarthritis (OA) contributing to the degenerative process. In these conditions, high levels of pro-inflammatory cytokines such as interleukin(IL)-1 $\beta$ have been found in synovial fluids and may participate in collagen and proteoglycan degradation [1,2]. Moreover, chondrocyte activation by proinflammatory cytokines has been implicated in joint destruction through the production of catabolic enzymes and inflammatory mediators such as reactive oxygen species (ROS) and prostaglandin $\mathrm{E}_{2}\left(\mathrm{PGE}_{2}\right)[3,4]$.

ROS can modulate cell signaling and exert damaging effects on cartilage as a consecuence of extracellular matrix degradation or chondrocyte apoptosis [4-7]. Furthermore, studies examining the life span of articular chondrocytes have demonstrated that oxidative stress is related to premature senescence and may be responsible for the development of OA $[8,9]$.

The arachidonic acid metabolite $\mathrm{PGE}_{2}$, a mediator of inflammation and pain, is produced in OA chondrocytes stimulated by IL-1 $\beta$ by the coordinated induction of cyclooxygenase-2 (COX-2) and microsomal PGE synthase 1 (mPGES-1) [10]. Previous studies have suggested the interest of this last enzyme as a novel target for OA [10]. Although some studies have reported that mice lacking mPGES-1 do not show significant differences with respect to wild type animals in OA induced by surgical procedures [11], it is interesting to note that mPGES-1 defficiency results in milder arthritis and lower cartilage degradation [12].

Heme oxygenase-1 (HO-1) is induced by oxidative stress (reviewed in [13]) and can inhibit apoptosis in several cell types such as T cells $[14,15]$, endothelial cells [16] 
and enterocytes [17]. In human OA chondrocytes, HO-1 induction by low doses of sodium nitroprusside has been shown to protect against apoptosis induced by high doses of this agent [18]. We have reported previously that HO-1 expression in OA chondrocytes is down-regulated by pro-inflammatory cytokines such as IL-1 $\beta$, IL-17 y tumor necrosis factor- $\alpha$ but up-regulated by the antiinflammatory cytokine IL-10 [19]. Recently, we have also shown a protective effect of HO-1 induction on cartilage degradation [20]. We hypothesized that HO-1 could control metabolic processes in chondrocytes relevant in the progression of OA. Therefore, we have investigated whether HO-1 induction by cobalt protoporphyrin IX (CoPP) may modify cell viability and the production of oxidative stress and $\mathrm{PGE}_{2}$ in $\mathrm{OA}$ chondrocytes in primary culture, thus avoiding the phenotypic changes associated with cell culture [21].

\section{Material and methods}

\subsection{Reagents}

IL-1 $\beta$ was from Peprotech EC Ltd. (London, UK). COX-2 and mPGES-1 polyclonal antibodies were purchased from Cayman Chemical (Ann Arbor, MI, USA) and the HO1 antibody was from Stressgen (Victoria, Canada). The peroxidase-conjugated IgGs were purchased from Dako (Copenhagen, Denmark). [5,6,8,11,12,14,15(n)- $\left.{ }^{3} \mathrm{H}\right] \mathrm{PGE}_{2}$ was from GE Healthcare (Barcelona, Spain). Pre-designed small interfering RNA (siRNA) oligonucleotides and SiPORT ${ }^{\mathrm{TM}}$ Amine were purchased from Ambion Inc. (Austin, TX, USA). CoPP was purchased from Frontier Scientific Europe Ltd. (Carnforth, UK). Dihydrorhodamine 123 (DHR) was from Molecular Probes ${ }^{\circledR}$, (Invitrogen S.A., Barcelona, Spain). The rest of reagents were from Sigma Aldrich (St Louis, MO, USA). 


\subsection{Chondrocyte culture}

Cartilage specimens were obtained from 18 patients with the diagnosis of advanced OA undergoing total knee joint replacement. Samples were obtained under the Institutional Ethical Commitee approved protocol. Cartilage slices were removed from the femoral condyles and tibial plateaus and cut into small pieces. Chondrocytes were isolated by sequential enzymatic digestion: $1 \mathrm{~h}$ with $0.1 \mathrm{mg} / \mathrm{ml}$ hyaluronidase (Sigma) followed by $12 \mathrm{~h}$ with $2 \mathrm{mg} / \mathrm{ml}$ collagenase (type IA) (Sigma) in DMEM/Ham's F-12 (Sigma) containing penicillin $(100 \mathrm{U} / \mathrm{ml})$ and streptomycin $(100 \mu \mathrm{g} / \mathrm{ml})$ at $37^{\circ} \mathrm{C}$ in $5 \% \mathrm{CO}_{2}$ atmosphere. The digested tissue was filtered through a $70 \mu \mathrm{m}$ nylon mesh, washed and centrifuged. Cell viability was greater than $95 \%$ according to the Trypan blue exclusion test. The isolated chondrocytes were seeded at $2.5 \times 10^{5}$ cells/well in six-well plates. Cells were cultured in growth medium: DMEM/Ham's F-12 supplemented with $10 \%$ human serum, penicillin $(100 \mathrm{U} / \mathrm{ml})$ and streptomycin $(100 \mu \mathrm{g} / \mathrm{ml})$ in a humidified $5 \%$ $\mathrm{CO}_{2}$ incubator at $37^{\circ}$. Chondrocytes were allowed to grow until nearly confluence and then incubated with $\mathrm{CoPP}(10 \mu \mathrm{M})$ or vehicule for $1 \mathrm{~h}$ before stimulation with IL-1 $\beta$ $(100 \mathrm{U} / \mathrm{ml})$. In experiments using HO-1 siRNA $(100 \mathrm{nM}$, sense 5'GGCAGAGAAUGCUGAGUUCtt-3', antisense 5'-GAACUCAGCAUUCUCUGCCtg$\left.3^{\prime}\right)$, transfection was performed in SiPORT ${ }^{\mathrm{TM}}$ Amine following the manufacturer's recommendations, $24 \mathrm{~h}$ before other experimental procedures. A nonspecific siRNA (Ambion) was used as negative control. Determination of aggrecan was performed by ELISA using a kit from Biosource Europe S.A. (Nivelles, Belgium) with sensitivity of $0.9 \mathrm{ng} / \mathrm{ml}$. For lentivirus transduction of chondrocytes, OA chondrocytes isolated as indicated above were cultured in alginate [22]. The pellet of primary chondrocytes $\left(1.5 \times 10^{6} / \mathrm{ml}\right)$ was resuspended in sterile alginate $(2 \%$ in $0.15 \mathrm{M} \mathrm{NaCl})$ and slowly added 
dropwise into a solution containing $100 \mathrm{mM} \mathrm{CaCl}_{2}$ (alginate- $\mathrm{CaCl}_{2}, 1 / 2(\mathrm{v} / \mathrm{v})$ ). The alginate beads polymerized in the presence of $\mathrm{CaCl}_{2}$ after 10 minutes and they were washed three times with $0.15 \mathrm{M} \mathrm{NaCl}$ solution and twice with growth medium. Chondrocytes in alginate beads were cultured for 10 days in growth medium supplemented with $25 \mu \mathrm{g} / \mathrm{ml}$ ascorbic acid.

\subsection{Transduction with lentiviral vectors}

Human embryonic kidney (HEK) 293T cells were grown in DMEM/Ham's F-12 supplemented with $10 \%$ human serum, penicillin $(100 \mathrm{U} / \mathrm{ml})$ and streptomycin $(100$ $\mu \mathrm{g} / \mathrm{ml})$ in a humidified $5 \% \mathrm{CO}_{2}$ incubator at $37^{\circ} \mathrm{C}$. For lentiviral production we used the expression vectors psPAX2, pMD2G and pWXL (Dr T. Didier, School of Life Sciences, Ecole Polytechnique Fédérale de Lausanne, Lausanne, Switzerland). Plasmid pWXL (green fluorescence protein (GFP) minus)Flag-hHO-1 was generated in two steps: first, the GFP coding sequence was replaced by an oligonucleotide cloned between the BamHI and EcoRI sites of pWXL (forward: 5'CGCGTATTCGGTCACCGTAAG-3' ${ }^{\prime}$ and 5'AATTCTTACGGTGACCGAATA-3'); second, the amplification product using pFlaghHO-1 as template and the following primers (forward:5'TCGCGGATCCATGGACTACAAAGACGATGA-3' and reverse: 5'TCCGGAATTCTGGTACCGATATCAGATCTAT-3') was digested with BamHI/EcoRI and subcloned in the same sites of pWXL (GFP)minus). Lentiviral vector stocks were generated in HEK293T cells by calcium phosphate-mediated transient transfection of three plasmids: the transfer vector plasmid (pWXL-Flag-hHO1), the packaging plasmid psPAX2, and the VSV-G envelope protein-coding plasmid pMD2G. After transfection for 24 and $48 \mathrm{~h}$, the cellular supernatants were removed, 
centrifuged at $700 \mathrm{~g}$ for $10 \mathrm{~min}$ at $4^{\circ} \mathrm{C}$, passed through $45 \mu \mathrm{m}$ pore size filters and kept at $-80^{\circ} \mathrm{C}$. The titers of lentiviral stocks were in the range of $3-5 \times 10^{5} \mathrm{IU} / \mathrm{ml}$ as determined by immunocytochemical analysis of HEK293T-infected cells [23]. The three-dimension chondrocyte culture in alginate was infected with $500 \mu \mathrm{l}$ of each lentiviral stock for $24 \mathrm{~h}$ in a humidified $5 \% \mathrm{CO}_{2}$ incubator at $37^{\circ} \mathrm{C}$. After infection and culture in growth medium for two days, alginate beads were stimulated with IL-1 $\beta(100 \mathrm{U} / \mathrm{ml})$ for $24 \mathrm{~h}$. Finally, HO-1 and mPGES-1 expression was measured by immunocytochemical analysis. The beads were fixed with $4 \%$ formaldehyde in PBS for 10 minutes and incubated with two antibodies at the same time: anti-FLAG monoclonal antibody (Sigma, 1/400) and anti-mPGES-1 polyclonal antibody (Cayman Chemical, 1/50) for $1.5 \mathrm{~h}$, followed by incubation with the secondary antibodies Alexa Fluor 488 goat antimouse IgG (Invitrogen) and R-phycoerythrin goat anti-rabbit IgG (Invitrogen) for 45 minutes at $37^{\circ} \mathrm{C}$. Cell nuclei were counterstained with 4',6'-diamidino-2-phenylindole (DAPI) solution (1/1000). Slides were examined under a fluorescence microscope (Eclipse E800, Nikon Instruments Europe, Amstelveen, The Netherlands). Each experiment was performed in triplicate.

\subsection{Determination of $P G E_{2}$}

Chondrocytes in primary culture were stimulated with IL-1 $\beta(100 \mathrm{U} / \mathrm{ml})$ or IL$1 \beta+\operatorname{CoPP}(10 \mu \mathrm{M})$ for $24 \mathrm{~h}$. Supernatants were harvested and frozen at $-80^{\circ} \mathrm{C}$ until analysis. $\mathrm{PGE}_{2}$ was measured by radioimmunoassay [24]. In another set of experiments, chondrocytes in primary culture were stimulated with IL-1 $\beta(100 \mathrm{U} / \mathrm{ml})$ for $24 \mathrm{~h}$ to induce COX-2 and mPGES-1, and then cells were washed with medium and incubated with arachidonic acid $(10 \mu \mathrm{M})$ and either CoPP or NS-398 $(10 \mu \mathrm{M})$. After $3 \mathrm{~h}$, supernatants were harvested and $\mathrm{PGE}_{2}$ measured as above. 


\subsection{Western blotting}

After $24 \mathrm{~h}$ stimulation with IL-1 $\beta(100 \mathrm{U} / \mathrm{ml})$ or IL- $1 \beta+\operatorname{CoPP}(10 \mu \mathrm{M})$, chondrocytes in primary culture were lysed in $100 \mu$ of buffer ( $1 \%$ Triton X-100, 1\% deoxycholic acid, $20 \mathrm{mM} \mathrm{NaCl}$ and $25 \mathrm{mM}$ Tris, $\mathrm{pH} 7.4$ ) and centrifuged at $4^{\circ} \mathrm{C}$ for $10 \mathrm{~min}$ at $10,000 \times \mathrm{g}$. Proteins $(25 \mu \mathrm{g})$ in cell lysates were separated by $12.5 \%$ SDS-PAGE and transferred onto polyvinylidene difluoride membranes. Membranes were blocked with 3\% bovine serum albumin and incubated with specific antibodies (1:1000) for $2 \mathrm{~h}$ at room temperature. Finally, membranes were incubated with peroxidase-conjugated goat antirabbit IgG and the immunoreactive bands were visualized by enhanced chemiluminescence (GE Healthcare) using the AutoChemi image analyzer (UVP Inc., Upland, CA,USA).

\subsection{Oxidative stress and apoptosis}

Oxidative stress and apoptosis rate were assessed by laser scanning cytometry (LSC) analysis. Chondrocytes $(75,000 /$ well were spread in 8-well Lab-tek chambers (Nalge Nunc International, Naperville, IL, USA) with DMEM/Ham's F-12, penicillin (100 $\mathrm{U} / \mathrm{ml})$, streptomycin $(100 \mu \mathrm{g} / \mathrm{ml})$ and $10 \%$ human serum in a humidified $5 \% \mathrm{CO}_{2}$ incubator at $37^{\circ} \mathrm{C}$. Confluent cells were treated with IL-1 $\beta(100 \mathrm{U} / \mathrm{ml})$ or IL- $1 \beta+\mathrm{CoPP}$ $(10 \mu \mathrm{M})$ for $24 \mathrm{~h}$. Analysis of viability and apoptosis was made using LSC Bx50 CompuCyte Olympus, (Cambridge, MA, USA) using the Vybrant Apoptosis Assay Kit (Molecular Probes ${ }^{\circledR}$, Invitrogen S.A.), according to the manufacturer's protocol. In this assay the externalization of phosphatidylserine, a marker of apoptosis, is detected by annexin V-FITC binding. Apoptotic cell death was also determined by the terminal 
deoxynucleotidyl transferase-mediated dUTP nick-end labeling (TUNEL) method using an assay kit (Roche Applied Science, Barcelona, Spain).

Formation of intracellular ROS was detected using DHR which is oxidized to fluorescent rhodamine (excitation at $485 \mathrm{~nm}$ and emission at $534 \mathrm{~nm}$ ). Chondrocytes (75,000/well) were incubated with DMEM without phenol red and DHR $(5 \mu \mathrm{M})$ for 15 min at $37^{\circ} \mathrm{C}$. After washing, fresh medium was added and cells were incubated with CoPP for $4 \mathrm{~h}$ and then with IL- $1 \beta$ in the presence or absence of CoPP for other $30 \mathrm{~min}$. Cultures were washed twice with fresh medium and analyzed by LSC.

\subsection{Real-time PCR}

Chondrocytes in primary culture were stimulated with IL-1 $\beta(100 \mathrm{U} / \mathrm{ml})$ or IL$1 \beta+\mathrm{CoPP}(10 \mu \mathrm{M})$ for $12 \mathrm{~h}$. Total RNA was extracted using the TRIzol reagent (Life Technologies Inc. Barcelona, Spain) according to the manufacturer's instructions. Reverse transcription was accomplished on $1 \mu \mathrm{g}$ of total RNA using random primers (TaqMan reverse transcription reagents, Applied Biosystems Spain, Madrid). PCR assays were performed in duplicate on an iCycler Real-Time PCR Detection System using SYBR Green PCR Master Mix (Bio-Rad Laboratories, Richmond, CA, USA) as previously described [20]. Primer sequences are shown in table 1. Cycle threshold (CT) values for each gene were corrected using the mean CT value for $\beta$-actin. Relative gene expression was calculated using the $\Delta \mathrm{C}_{\mathrm{T}}$ method and expressed as fold change $\left(2^{-\Delta \Delta \mathrm{C}} \mathrm{T}\right)$ relative to the expression values in nonstimulated cells.

\subsection{Activation of transcription factors}

Chondrocytes were seeded into 6-well plates and grown to 50-60\% confluence. Transient transfection was performed overnight with $2 \mu \mathrm{g}$ of the reporter construct 
nuclear factor- $\kappa \mathrm{B}(\mathrm{NF}-\kappa \mathrm{B})-\mathrm{luc}$, activator protein(AP-1)-luc or early growth response(EGR)-1-luc (Stratagene, La Jolla, CA, USA) and $1 \mu \mathrm{g}$ of the internal control pRL-TK (Promega Corporation, Madison, WI, USA) by the Magnetofection ${ }^{\mathrm{TM}}$ system (OZ Biosciences, Marseille, France) according to the manufacturer's recommendations. The medium was then replaced and after $18 \mathrm{~h}$ cells were treated for $24 \mathrm{~h}$ with CoPP in the absence or presence of IL-1 $\beta(100 \mathrm{U} / \mathrm{ml})$. After lysis and centrifugation, aliquots of supernatants were used to assay firefly and Renilla luciferase activity using the DualLuciferase Reporter Assay System kit (Promega Corporation). Luminescence was measured in a Microbeta counter (Wallac, Turku, Finland) and firefly luciferase activity was normalized to Renilla luciferase activity.

\subsection{Data analysis}

Results are presented as mean \pm SEM. Statistical analyses were performed using oneway ANOVA followed by Dunnett's $t$-test for multiple comparisons and unpaired Student's $t$-test for dual comparisons.

\section{Results}

\subsection{HO-1 induction increases chondrocyte viability}

According to previous studies [20], we used CoPP $(10 \mu \mathrm{M})$ to induce HO-1 in OA chondrocytes. To determine whether cell viability is modified in our experimental conditions, we performed LSC experiments. We observed a significant reduction in cell viability after IL-1 $\beta$ treatment for $24 \mathrm{~h}$ (Fig. 1A), which was counteracted by CoPP. We determined whether HO-1 induction by CoPP was able to control apoptosis, an important factor in the evolution of OA [29]. Fig. 1B shows that IL-1 $\beta$ weakly induced 
apoptosis measured by LSC (annexin V-FITC) and CoPP treatment significantly reduced the rate of apoptosis to basal levels. Our results suggest that CoPP effects on apoptosis were specific, as in cells treated with HO-1 siRNA, CoPP failed to modify this process. Additional experiments using the TUNEL method (Fig. 1C) confirmed the beneficial effects of CoPP treatment on chondrocyte apoptosis in the presence of IL-1 $\beta$, although the level of apoptosis induced by this cytokine was a bit higher in this assay, with percentages of $11.4 \pm 2.3(\mathrm{~B}), 6.2 \pm 2.2$ (CoPP), $21.2 \pm 5.3$ (IL-1 $\beta$ ) and 12.0 \pm 2.9 (IL$1 \beta+\mathrm{CoPP}, n=6, p<0.05$ with respect to IL-1 $\beta)$.

The ability to synthesize extracellular matrix components is a feature of chondrocyte metabolism. Our results indicate that CoPP treatment was also able to counteract the loss of aggrecan induced by IL-1 $\beta$. Treatment with this cytokine for $24 \mathrm{~h}$ reduced aggrecan content in chondrocytes from $11618 \pm 1664$ to $7699 \pm 567 \mathrm{ng}$ proteoglycan/mg protein $(n=6, p<0.05)$. In contrast, chondrocytes treated with CoPP+IL-1 $\beta$ showed proteoglycan levels similar to those of non-stimulated cells (12063 \pm 522 , ng proteoglycan $/ \mathrm{mg}$ protein, $n=6, p<0.05$ with respect to IL-1 $\beta$ ). Thus, our investigations suggest that overexpression of HO-1 confers to OA chondrocytes an increased resistance to the deleterious effects of IL-1 $\beta$.

\subsection{HO-1 induction inhibits oxidative stress}

Since many of the effects of IL-1 $\beta$ on chondrocyte metabolism are mediated by the generation of ROS, we wanted to determine whether the production of oxidative stress could be modified by HO-1 induction. Stimulation of chondrocytes by this cytokine resulted in a significant level of ROS generation (Fig. 2). Consistent with an antioxidative role for HO-1 induction, oxidative stress was significantly decreased in cells treated with CoPP. The effect of HO-1 induction was confirmed in experiments 
using HO-1 siRNA as this agent prevented the down-regulation of ROS production by CoPP treatment.

\subsection{Effects on $P G E_{2}, C O X-2$ and $\mathrm{MPGES}-1$}

As a result of COX-2 and mPGES-1 induction, IL-1 $\beta$ strongly increased PGE $_{2}$ levels after chondrocyte stimulation for $24 \mathrm{~h}$. Production of $\mathrm{PGE}_{2}$ was significantly reduced in cells treated with CoPP and stimulated with IL-1 $\beta$ (Fig. 3A). To confirm that CoPP effects were due to the induction of HO-1, we used a siRNA specific for human HO- 1 . This agent nearly abolished the induction of $\mathrm{HO}-1$ protein by $\mathrm{CoPP}$, whereas a nonspecific siRNA failed to modify HO-1 protein expression (Fig. 3B). Interestingly, the treatment with the first siRNA reverted the inhibitory effects of CoPP on $\mathrm{PGE}_{2}$ (Fig. 3A). The possible contribution of inhibitory effects on enzymatic activities regulating $\mathrm{PGE}_{2}$ synthesis was tested by using chondrocytes previously treated with IL-1 $\beta$ for $24 \mathrm{~h}$ to induce COX-2 and mPGES-1 and then washed and incubated in fresh medium with CoPP and arachidonic acid for $3 \mathrm{~h}$. In this experimental setting, the production of $\mathrm{PGE}_{2}$ was dramatically increased in cells treated with IL-1 $\beta$ in comparison with nonstimulated cells (119.3 \pm 21.6 versus $9.2 \pm 1.2 \mathrm{ng} / \mathrm{mg}$ protein, $n=8, p<0.01)$. As expected, the COX-2 inhibitor NS-398 $(10 \mu \mathrm{M})$ reduced $\mathrm{PGE}_{2}$ production to basal levels $(5.9 \pm 1.2$, $p<0.01)$ but CoPP $(10 \mu \mathrm{M})$ was devoid of significant effects $(113.5 \pm 13.7 \mathrm{ng} / \mathrm{mg}$ protein). We investigated whether the effects of $\mathrm{HO}-1$ induction on $\mathrm{PGE}_{2}$ were the consequence of a reduced expression of COX-2 or mPGES-1. As shown in Fig. 3B, IL$1 \beta$ induced the expression of COX-2 and mPGES-1 in OA chondrocytes. CoPP treatment down-regulated mPGES-1 protein whereas HO-1 siRNA tended to revert this effect. In contrast, COX-2 expression was not significantly modified by CoPP. The ability of CoPP to reduce mPGES-1 expression was also observed at the mRNA level 
(Table 2). To confirm that HO-1 overexpression results in reduced mPGES-1 expression, a three-dimension culture of $\mathrm{OA}$ chondrocytes was transduced with a lentiviral HO-1 vector (LV-HO-1). Fig. 4 shows that mPGES-1 was strongly induced by IL-1 $\beta$ in cells transduced with the empty vector LV-. In contrast, in cells transduced with LV-HO-1, mPGES-1 was hardly detected after IL-1 $\beta$ stimulation.

\subsection{Effects on the activation of transcription factors}

Because NF- $\kappa \mathrm{B}$ is a main regulator of pro-inflammatory genes, we analyzed the contribution of this transcription factor to the effects of CoPP. As shown in Fig. 5A, IL$1 \beta$ activated NF- $\kappa B$ in OA chondrocytes. Although CoPP treatment of cells did not modify basal luciferase activity, it significantly decreased the activation of this transcription factor in the presence of IL-1 $\beta$. In contrast, the activation of AP-1, another transcription factor involved in the expression of pro-inflammatory genes [30], was not influenced by CoPP (Fig. 5B). As EGR-1 is a key transcription factor in regulating the inducible expression of mPGES-1 [31], we investigated the effects of CoPP treatment on EGR-1 activation. When IL-1 $\beta$ was incubated with chondrocytes, EGR-1 activity was significantly enhanced. It is interesting that the treatment of chondrocytes with CoPP led to a significant reduction of EGR-1-luc promoter activation in cells stimulated with IL-1 $\beta$ as well as in non-stimulated cells (Fig. 5C).

\section{Discussion}

Pro-inflammatory cytokines such as IL- $1 \beta$ induce the formation of intracellular oxidants which may function as second messengers leading to augmentation of gene expression of degradative enzymes [32]. In addition, ROS have been implicated in cartilage degeneration in OA through the initiation of chondrocyte apoptosis [33], decreased 
replicative potential, catabolic changes in matrix cartilage, telomere instability and senescence [8]. It is known that HO-1 induction can decrease the levels of the prooxidant heme and increase the generation of antioxidant molecules (biliverdin and bilirubin) and the anti-apoptotic and anti-inflammatory agent carbon monoxide (reviewed in [13]). In the present study we provide evidence of a protective role for HO1 induction against oxidative stress in human OA chondrocytes. Our results also suggest that inhibition of ROS generation may contribute to the beneficial effects of CoPP on viability, apoptosis and extracellular matrix metabolism in primary OA chondrocytes. Therefore, the antioxidant properties of HO-1 may be relevant for its chondroprotective effect.

Previous studies have demonstrated an increased expresion of COX-2 and mPGES-1 in OA cartilage [28] and chondrocytes [34]. Experimental evidence indicate that IL-1 $\beta$ induces in chondrocytes large elevations of COX-2 and mPGES-1 leading to increased levels of $\mathrm{PGE}_{2}$. Besides its pro-inflammatory effects, this mediator can participate in the catabolic-anabolic imbalance in OA by inhibiting tissue inhibitor of metalloproteinases-1 synthesis or enhancing matrix metalloproteinase production [35,36]-[37]. In contrast, low concentrations of $\mathrm{PGE}_{2}$ may downregulate collagenases and collagen 2A1 cleavage [38]. $\mathrm{PGE}_{2}$ may enhance chondrocyte death [39] and induce apoptosis in bovine articular chondrocytes through the cAMP pathway [40]. In this study, we investigated the effects of HO-1 induction on IL-1 $\beta$-stimulated $\mathrm{PGE}_{2}$ production in primary OA chondrocytes. We have shown that these effects were not dependent on the inhibition of COX-2/mPGES-1 enzyme activity. Although the reduction in heme availability may result in COX-2 protein possessing a low activity, our recent data [41] suggest that a product of HO-1 activity such as $\mathrm{CO}$ may be responsible for the reductions in $\mathrm{PGE}_{2}$ production after $\mathrm{HO}-1$ induction. Our results 
have demonstrated the down-regulation of mPGES-1 gene expression by HO-1 that translates into accompanying declines in $\mathrm{PGE}_{2}$ production. This may result in the control of $\mathrm{PGE}_{2}$ overproduction during inflammatory responses without inhibition of other metabolites derived from COX-2 activity, with possible protective effects [42]. Recently, we have reported that HO-1 protects against cartilage degradation through the inhibition of the expression of several matrix metalloproteinases [20]. Here, we show for the first time a regulatory role of $\mathrm{HO}-1$ in $\mathrm{PGE}_{2}$ production due to mPGES-1 modulation, in primary OA chondrocytes stimulated with IL-1 $\beta$, which may participate in the observed protective effects on cartilage.

$\mathrm{NF}-\kappa \mathrm{B}$ and AP-1 are involved in the transcription of a number of inflammatory genes and MMPs $[30,43]$. Our data suggest that the inhibitory effects of HO-1 induction on the first transcription factor could play a role in the recently reported inhibition of MMP expresion [20]. Although the COX-2 promoter contains multiple regulatory sites including those able to interact with both transcription factors, it has been reported that COX-2 induction by IL- $1 \beta$ in human chondrocytes may be dependent on other transcription factors [44], which would be consistent with the lack of effect of CoPP on COX-2 expression.

mPGES-1 is induced by pro-inflammatory cytokines in many cell types and has been proposed as a target in inflammatory diseases [45] and OA [10,46]. Recent studies have revealed that EGR-1 could be a key regulator of mPGES-1 transcription in response to cytokine stimulation [47]. Therefore, we sought to establish whether HO-1 induction could regulate this transcription factor. Our data have shown that HO-1 induction results in a significant decrease of EGR-1 activation in primary OA chondrocytes stimulated with IL-1 $\beta$, thus providing a mechanism for the inhibition of mPGES-1 expression. Previous studies from our lab have shown the inhibitory effects 
of HO-1 induction on extracellular signal related kinase-1/2 phosphorylation [20]. This mechanism may also participate in the down-regulation of mPGES-1 by HO-1 induction, as the activity of mitogen activated protein kinases could be critical for the expression of mPGES-1 [10].

Therefore, HO-1 induction has shown consistent inhibitory effects toward a number of processes involved in the pathology and progression of OA. The present data revealed new facets of HO-1 actions in OA chondrocytes that could be relevant to cell survival in cartilage degeneration. These studies open the potential for therapy for a range of inflammatory and degenerative conditions and provide an opportunity to clarify HO-1 effects in human articular cells.

\section{Acknowledgements}

This work was supported by grant SAF2007-61769 (Plan Nacional I+D+I-FEDER). J. Megías thanks Spanish Ministerio de Educación y Ciencia, and Victoria Clérigues thanks Generalitat Valenciana, for predoctoral fellowships. 


\section{References}

[1] Dodge GR, Poole AR. Immunohistochemical detection and immunochemical analysis of type II collagen degradation in human normal, rheumatoid, and osteoarthritic articular cartilages and in explants of bovine articular cartilage cultured with interleukin 1. J Clin Invest 1989;83: 647-61

[2] van der Kraan PM, van den Berg WB. Anabolic and destructive mediators in osteoarthritis. Curr Opin Clin Nutr Metab Care 2000;3: 205-11

[3] Attur MG, Patel IR, Patel RN, Abramson SB, Amin AR. Autocrine production of IL-1 beta by human osteoarthritis-affected cartilage and differential regulation of endogenous nitric oxide, IL-6, prostaglandin E2, and IL-8. Proc Assoc Am Physicians 1998;110: 65-72

[4] Henrotin YE, Bruckner P, Pujol JP. The role of reactive oxygen species in homeostasis and degradation of cartilage. Osteoarthritis Cartilage 2003;11: 74755

[5] Burkhardt H, Schwingel M, Menninger H, Macartney HW, Tschesche H. Oxygen radicals as effectors of cartilage destruction. Direct degradative effect on matrix components and indirect action via activation of latent collagenase from polymorphonuclear leukocytes. Arthritis Rheum 1986;29: 379-87

[6] Clancy R, Rediske J, Koehne C, Stoyanovsky D, Amin A, Attur M et al. Activation of stress-activated protein kinase in osteoarthritic cartilage: evidence for nitric oxide dependence. Osteoarthritis Cartilage 2001;9: 294-9

[7] Yoon SO, Park SJ, Yoon SY, Yun CH, Chung AS. Sustained production of $\mathrm{H}(2) \mathrm{O}(2)$ activates pro-matrix metalloproteinase-2 through receptor tyrosine kinases/phosphatidylinositol 3-kinase/NF-kappa B pathway. J Biol Chem 2002;277: $30271-82$ 
[8] Yudoh K, Nguyen T, Nakamura H, Hongo-Masuko K, Kato T, Nishioka K. Potential involvement of oxidative stress in cartilage senescence and development of osteoarthritis: oxidative stress induces chondrocyte telomere instability and downregulation of chondrocyte function. Arthritis Res Ther 2005;7: R380-R391

[9] Dai SM, Shan ZZ, Nakamura H, Masuko-Hongo K, Kato T, Nishioka K et al. Catabolic stress induces features of chondrocyte senescence through overexpression of caveolin 1: possible involvement of caveolin 1-induced downregulation of articular chondrocytes in the pathogenesis of osteoarthritis. Arthritis Rheum 2006;54: 818-31

[10] Masuko-Hongo K, Berenbaum F, Humbert L, Salvat C, Goldring MB, Thirion S. Up-regulation of microsomal prostaglandin E synthase 1 in osteoarthritic human cartilage: critical roles of the ERK-1/2 and p38 signaling pathways. Arthritis Rheum 2004;50: 2829-38

[11] Yamakawa K, Kamekura S, Kawamura N, Saegusa M, Kamei D, Murakami M et al. Association of microsomal prostaglandin E synthase 1 deficiency with impaired fracture healing, but not with bone loss or osteoarthritis, in mouse models of skeletal disorders. Arthritis Rheum 2007;58: 172-83

[12] Trebino CE, Stock JL, Gibbons CP, Naiman BM, Wachtmann TS, Umland JP et al. Impaired inflammatory and pain responses in mice lacking an inducible prostaglandin E synthase. Proc Natl Acad Sci U S A 2003;100: 9044-9

[13] Alcaraz MJ, Fernandez P, Guillen MI. Anti-inflammatory actions of the heme oxygenase-1 pathway. Curr Pharm Des 2003;9: 2541-51 
[14] Pae HO, Choi BM, Oh GS, Lee MS, Ryu DG, Rhew HY et al. Roles of heme oxygenase- 1 in the antiproliferative and antiapoptotic effects of nitric oxide on Jurkat T cells. Mol Pharmacol 2004;66: 122-8

[15] Choi BM, Pae HO, Jeong YR, Oh GS, Jun CD, Kim BR et al. Overexpression of heme oxygenase (HO)-1 renders Jurkat $\mathrm{T}$ cells resistant to fas-mediated apoptosis: involvement of iron released by HO-1. Free Radic Biol Med 2004;36: 858-71

[16] Brouard S, Otterbein LE, Anrather J, Tobiasch E, Bach FH, Choi AM et al. Carbon monoxide generated by heme oxygenase 1 suppresses endothelial cell apoptosis. J Exp Med 2000;192: 1015-26

[17] Busserolles J, Megias J, Terencio MC, Alcaraz MJ. Heme oxygenase-1 inhibits apoptosis in Caco-2 cells via activation of Akt pathway. Int J Biochem Cell Biol 2006;38: 1510-7

[18] Kim HA, Lee KB, Bae SC. The mechanism of low-concentration sodium nitroprusside-mediated protection of chondrocyte death. Arthritis Res Ther 2005;7: R526-R535

[19] Fernandez P, Guillen MI, Gomar F, Alcaraz MJ. Expression of heme oxygenase-1 and regulation by cytokines in human osteoarthritic chondrocytes. Biochem Pharmacol 2003;66: 2049-52

[20] Guillen MI, Megias J, Gomar F, Alcaraz MJ. Heme oxygenase-1 regulates catabolic and anabolic processes in osteoarthritic chondrocytes. J Pathol 2008;214: 515-22

[21] von der MK, Gauss V, von der MH, Muller P. Relationship between cell shape and type of collagen synthesised as chondrocytes lose their cartilage phenotype in culture. Nature 1977;267: 531-2 
[22] Shakibaei M, de Souza P. Differentiation of mesenchymal limb bud cells to chondrocytes in alginate beads. Cell Biol Int 1997;21: 75-86

[23] Rojo AI, Sagarra MR, Cuadrado A. GSK-3beta down-regulates the transcription factor Nrf2 after oxidant damage: relevance to exposure of neuronal cells to oxidative stress. J Neurochem 2008;105: 192-202

[24] Moroney MA, Alcaraz MJ, Forder RA, Carey F, Hoult JRS. Selectivity of neutrophil 5-lipoxygenase and cyclo-oxygenase inhibition by an antiinflammatory flavonoid glycoside and related aglycone flavonoids. J Pharm Pharmacol 1988;40: 787-92

[25] Thilakawardhana S, Everett DM, Murdock PR, Dingwall C, Owen JS. Quantification of apolipoprotein E receptors in human brain-derived cell lines by real-time polymerase chain reaction. Neurobiol Aging 2005;26: 813-23

[26] Kasai K, Banba N, Hishinuma A, Matsumura M, Kakishita H, Matsumura M et al. 15-Deoxy-Delta(12,14)-prostaglandin $\mathrm{J}(2)$ facilitates thyroglobulin production by cultured human thyrocytes. Am J Physiol Cell Physiol 2000;279: C1859-C1869

[27] Daouti S, Latario B, Nagulapalli S, Buxton F, Uziel-Fusi S, Chirn GW et al. Development of comprehensive functional genomic screens to identify novel mediators of osteoarthritis. Osteoarthritis Cartilage 2005;13: 508-18

[28] Li X, Afif H, Cheng S, Martel-Pelletier J, Pelletier JP, Ranger P et al. Expression and regulation of microsomal prostaglandin E synthase-1 in human osteoarthritic cartilage and chondrocytes. J Rheumatol 2005;32: 887-95

[29] Heraud F, Heraud A, Harmand MF. Apoptosis in normal and osteoarthritic human articular cartilage. Ann Rheum Dis 2000;59: 959-65 
[30] Liacini A, Sylvester J, Li WQ, Zafarullah M. Inhibition of interleukin-1stimulated MAP kinases, activating protein-1 (AP-1) and nuclear factor kappa B (NF-kappa B) transcription factors down-regulates matrix metalloproteinase gene expression in articular chondrocytes. Matrix Biol 2002;21: 251-62

[31] Cheng S, Afif H, Martel-Pelletier J, Pelletier JP, Li X, Farrajota K et al. Activation of peroxisome proliferator-activated receptor gamma inhibits interleukin-1beta-induced membrane-associated prostaglandin E2 synthase-1 expression in human synovial fibroblasts by interfering with Egr-1. J Biol Chem 2004;279: 22057-65

[32] Lo YY, Conquer JA, Grinstein S, Cruz TF. Interleukin-1 beta induction of c-fos and collagenase expression in articular chondrocytes: involvement of reactive oxygen species. J Cell Biochem 1998;69: 19-29

[33] Del CM, Jr., Loeser RF. Nitric oxide-mediated chondrocyte cell death requires the generation of additional reactive oxygen species. Arthritis Rheum 2002;46: $394-403$

[34] Grimmer C, Pfander D, Swoboda B, Aigner T, Mueller L, Hennig FF et al. Hypoxia-inducible factor 1alpha is involved in the prostaglandin metabolism of osteoarthritic cartilage through up-regulation of microsomal prostaglandin $\mathrm{E}$ synthase 1 in articular chondrocytes. Arthritis Rheum 2007;56: 4084-94

[35] Yamada H, Kikuchi T, Nemoto O, Obata K, Sato H, Seiki M et al. Effects of indomethacin on the production of matrix metalloproteinase- 3 and tissue inhibitor of metalloproteinases-1 by human articular chondrocytes. J Rheumatol 1996;23: 1739-43

[36] Shapiro SD, Kobayashi DK, Pentland AP, Welgus HG. Induction of macrophage metalloproteinases by extracellular matrix. Evidence for enzyme- 
and substrate-specific responses involving prostaglandin-dependent mechanisms. J Biol Chem 1993;268: 8170-5

[37] Hardy MM, Seibert K, Manning PT, Currie MG, Woerner BM, Edwards D et al. Cyclooxygenase 2-dependent prostaglandin E2 modulates cartilage proteoglycan degradation in human osteoarthritis explants. Arthritis Rheum 2002;46: 1789803

[38] Tchetina EV, Di Battista JA, Zukor DJ, Antoniou J, Poole AR. Prostaglandin PGE2 at very low concentrations suppresses collagen cleavage in cultured human osteoarthritic articular cartilage: this involves a decrease in expression of proinflammatory genes, collagenases and COL10A1, a gene linked to chondrocyte hypertrophy. Arthritis Res Ther 2007;9: R75

[39] Notoya K, Jovanovic DV, Reboul P, Martel-Pelletier J, Mineau F, Pelletier JP. The induction of cell death in human osteoarthritis chondrocytes by nitric oxide is related to the production of prostaglandin E2 via the induction of cyclooxygenase-2. J Immunol 2000;165: 3402-10

[40] Miwa M, Saura R, Hirata S, Hayashi Y, Mizuno K, Itoh H. Induction of apoptosis in bovine articular chondrocyte by prostaglandin E(2) through cAMPdependent pathway. Osteoarthritis Cartilage 2000;8: 17-24

[41] Guillen MI, Megias J, Clerigues V, Gomar F, Alcaraz MJ. The CO-releasing molecule CORM-2 is a novel regulator of the inflammatory process in osteoarthritic chondrocytes. Rheumatology (Oxford) 2008;47: 1323-8

[42] Gilroy DW, Colville-Nash PR, Willis D, Chivers J, Paul-Clark MJ, Willoughby DA. Inducible cyclooxygenase may have anti-inflammatory properties. Nat Med 1999;5: 698-701 
[43] Xiao W, Advances in NF-kappaB signaling transduction and transcription. Cell Mol Immunol 2004;1: 425-35

[44] Thomas B, Berenbaum F, Humbert L, Bian H, Bereziat G, Crofford L et al. Critical role of C/EBPdelta and C/EBPbeta factors in the stimulation of the cyclooxygenase-2 gene transcription by interleukin-1beta in articular chondrocytes. Eur J Biochem 2000;267: 6798-809

[45] Stichtenoth DO, Thoren S, Bian H, Peters-Golden M, Jakobsson PJ, Crofford LJ. Microsomal prostaglandin E synthase is regulated by proinflammatory cytokines and glucocorticoids in primary rheumatoid synovial cells. J Immunol 2001;167: 469-74

[46] Kojima F, Naraba H, Miyamoto S, Beppu M, Aoki H, Kawai S. Membraneassociated prostaglandin E synthase-1 is upregulated by proinflammatory cytokines in chondrocytes from patients with osteoarthritis. Arthritis Res Ther 2004;6: R355-R365

[47] Naraba H, Yokoyama C, Tago N, Murakami M, Kudo I, Fueki M et al. Transcriptional Regulation of the Membrane-associated Prostaglandin E2 Synthase Gene. Essential role of transcription factor Egr-1. J Biol Chem 2002;277: $28601-8$ 


\section{FIGURE LEGENDS}

Fig. 1. Effect of CoPP on viability and apoptosis of OA chondrocytes. (A) Viability by the LSC assay. (B) Apoptosis by the LSC assay. Cells in primary culture were stimulated with IL-1 $\beta(100 \mathrm{U} / \mathrm{ml})$ in the presence or absence of CoPP $(10 \mu \mathrm{M})$ and siRNA specific for HO-1 or siRNA control (100 $\mathrm{nM})$. Data are expressed as mean $\pm \operatorname{SEM}(n=6-8) .{ }^{* *} p<0.01$ with respect to IL-1 $\beta ; \# \# P<0.01$ with respect to nonstimulated cells. (C) TUNEL assay: B (nonstimulated cells). The picture is representative of results from three separate experiments. Magnification x200.

Fig. 2. Effect of CoPP on oxidative stress in human OA chondrocytes. Cells were stimulated with IL-1 $\beta(100 \mathrm{U} / \mathrm{ml})$ in the presence or absence of CoPP $(10 \mu \mathrm{M})$ and a siRNA specific for HO-1 or siRNA control (100 nM). Oxidative stress were measured by LSC, as indicated in Materials and methods. Data are expressed as mean $\pm \mathrm{SEM}$ $(n=8) .{ }^{*} p<0.01$ with respect to IL-1 $;$; \#\#p<0.01 with respect to nonstimulated cells. Rho: rhodamine.

Fig. 3. Effect of CoPP on (A) $\mathrm{PGE}_{2}$ levels and (B) COX-2, mPGES-1 and HO-1 protein expression in human OA chondrocytes. Cells were stimulated with IL-1 $\beta(100 \mathrm{U} / \mathrm{ml})$ for $24 \mathrm{~h}$ in the presence or absence of CoPP $(10 \mu \mathrm{M})$. $\mathrm{PGE}_{2}$ was measured in supernatants by radioimmunoassay and protein expression was determined in cell lysates by Western blotting. Data are expressed as mean \pm S.E.M. $(n=10-15) .{ }^{* *} p<0.01$ with respect to IL-1 $\beta ; \# \# p<0.01$ with respect to nonstimulated cells. The immunoblot is representative of three independent experiments. 
Fig. 4. Effect of HO-1 (after LV-HO-1 transduction) on mPGES-1 protein in OA chondrocytes stimulated by IL-1 $\beta$. Three-dimension cultures of OA chondrocytes in alginate were transduced with LV-HO-1 or the empty vector LV-. mPGES-1 expression was induced by IL-1 $\beta$ stimulation for $24 \mathrm{~h}$ and HO-1 and mPGES-1 expression was characterized by immunofluorescence. Cell nuclei were counterstained with DAPI. Fluorescence micrographs representative of three separate experiments. Magnification $\mathrm{x} 200$.

Fig. 5. Effect of CoPP on the activation of (A) NF-кB, (B) AP-1 and (C) EGR-1.

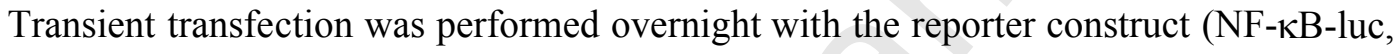
AP-1-luc or EGR-1-luc) and the internal control pRL-TK, as indicated in Materials and methods. Cells were treated for $24 \mathrm{~h}$ with CoPP in the absence or presence of IL-1 $\beta$ (100 U/ml). Firefly luciferase activity was normalized to Renilla luciferase activity. Data are expressed as mean $\pm \operatorname{SEM}(n=6)$. $* * p<0.01$ with respect to IL-1 $\beta$; $\# p<0.05$; $\# \# p<0.01$ with respect to nonstimulated cells. 
Table 1. Sequences of primers used in real-time PCR experiments

Forward Reverse

\begin{tabular}{|c|c|c|}
\hline $\begin{array}{l}\beta \text {-actin } \\
{[25]}\end{array}$ & 5'-AGGCTACGAGCTGCCTGACG-3' & 5'-GTAGTTTCGTGGATGCCACAGGACT-3' \\
\hline $\begin{array}{l}\mathrm{HO}-1 \\
{[26]}\end{array}$ & 5'-CAGGCAGAGAATGCTGAGTTC-3' & 5'-GCTTCACATAGCGCTGCA-3 \\
\hline $\begin{array}{l}\mathrm{COX}-2 \\
{[27]}\end{array}$ & 5'-AAATTGCTGGCAGGGTTGC-3' & 5'-TTTCTGTACTGCGGGTGGAAC-3' \\
\hline $\begin{array}{l}\text { mPGES-1 } \\
{[28]}\end{array}$ & 5'-GAAGAAGGCCTTTGCCAA-3' & 5'-GGAAGACCAGGAAGTGCATC-3' \\
\hline
\end{tabular}


Table 2. Relative gene expression of OA chondrocytes stimulated with IL-1 $\beta$.

$\begin{array}{llll}\text { Treatment } & \text { HO-1 } & \text { COX-2 } & \text { mPGES-1 }\end{array}$

$\begin{array}{llll}\text { IL-1 } \beta & -1.1 \pm 1.5 & 20.9 \pm 2.7 & 21.8 \pm 0.6 \\ \text { IL- } 1 \beta+\mathrm{CoPP} & 4.9 \pm 0.3^{*} & 21.7 \pm 1.7 & 15.7 \pm 0.7 *\end{array}$

Mean fold change $( \pm$ SEM, $n=5)$ in gene expression relative to control $12 \mathrm{~h}$ post stimulation. IL-1 $\beta$ : $100 \mathrm{U} / \mathrm{ml}$; CoPP: $10 \mu \mathrm{M} .{ }^{*} p<0.05$, with respect to IL-1 $\beta$. 


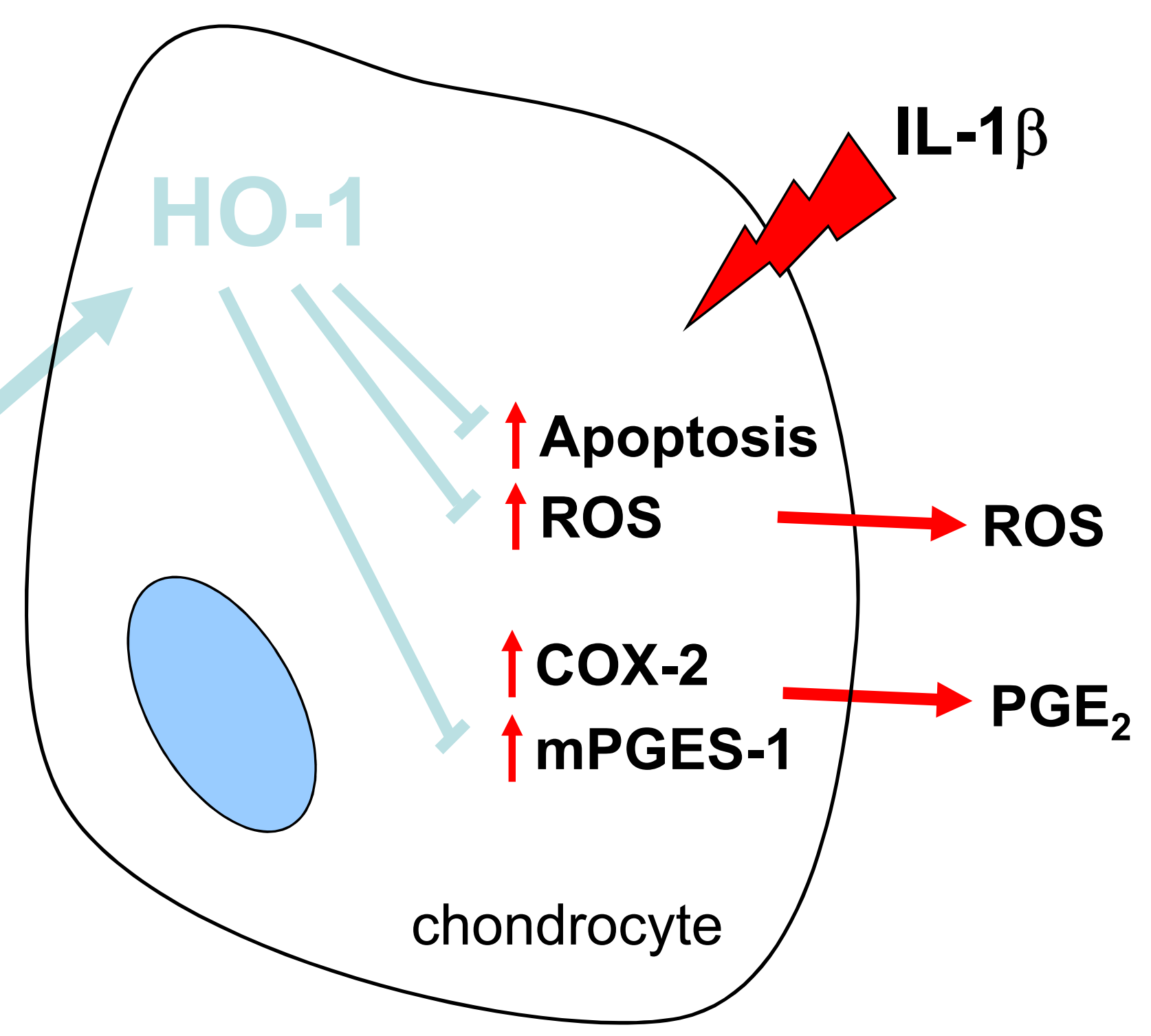




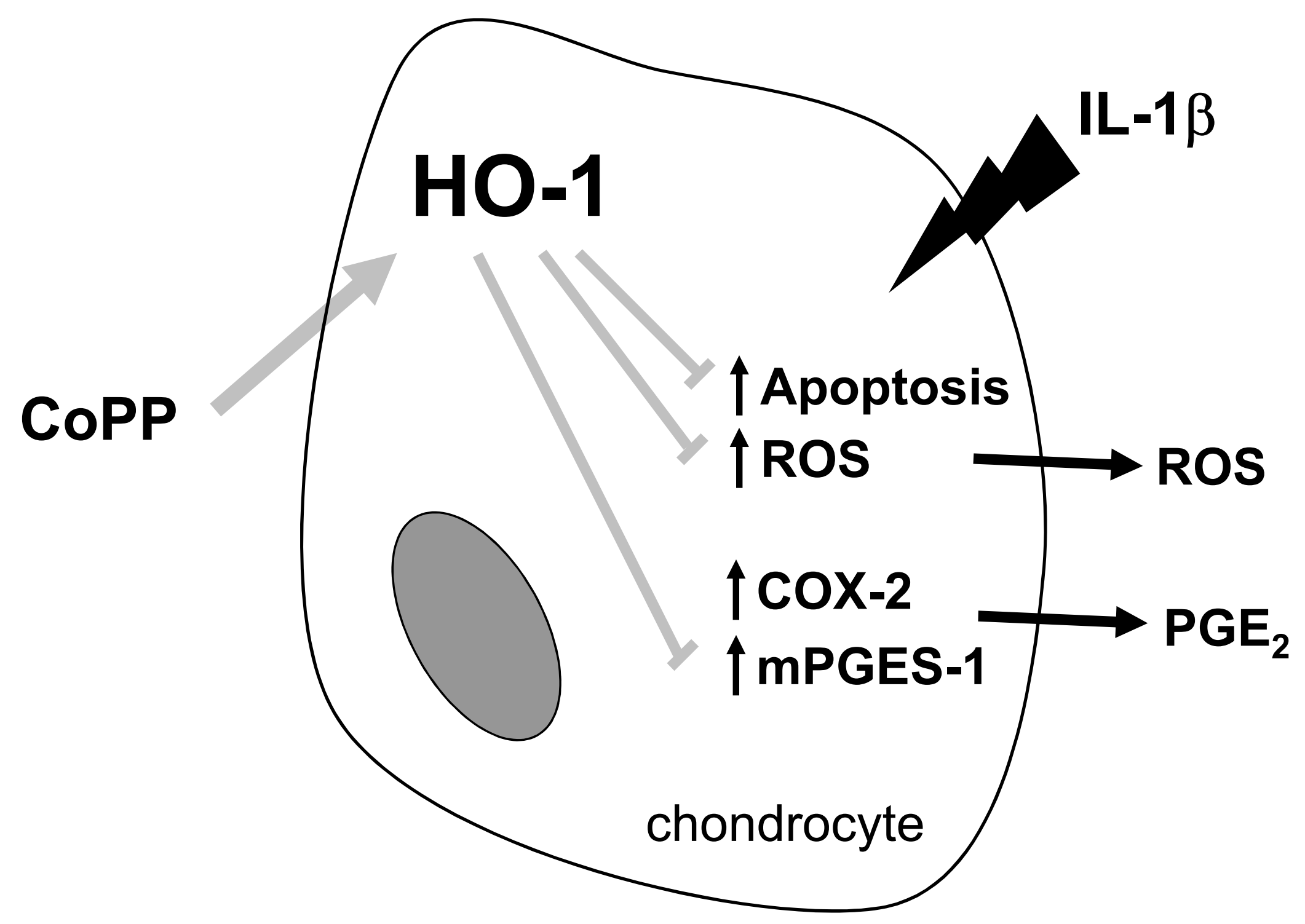


A

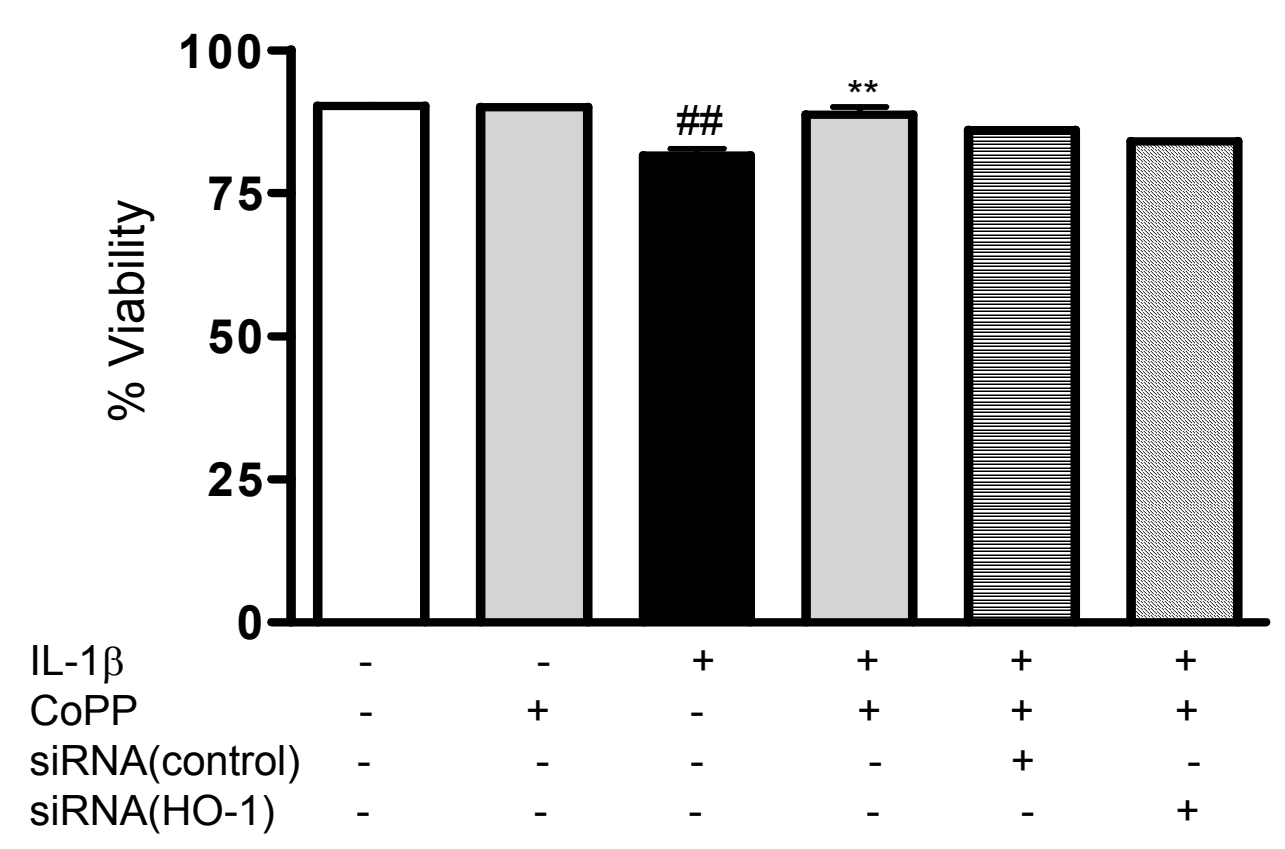

B

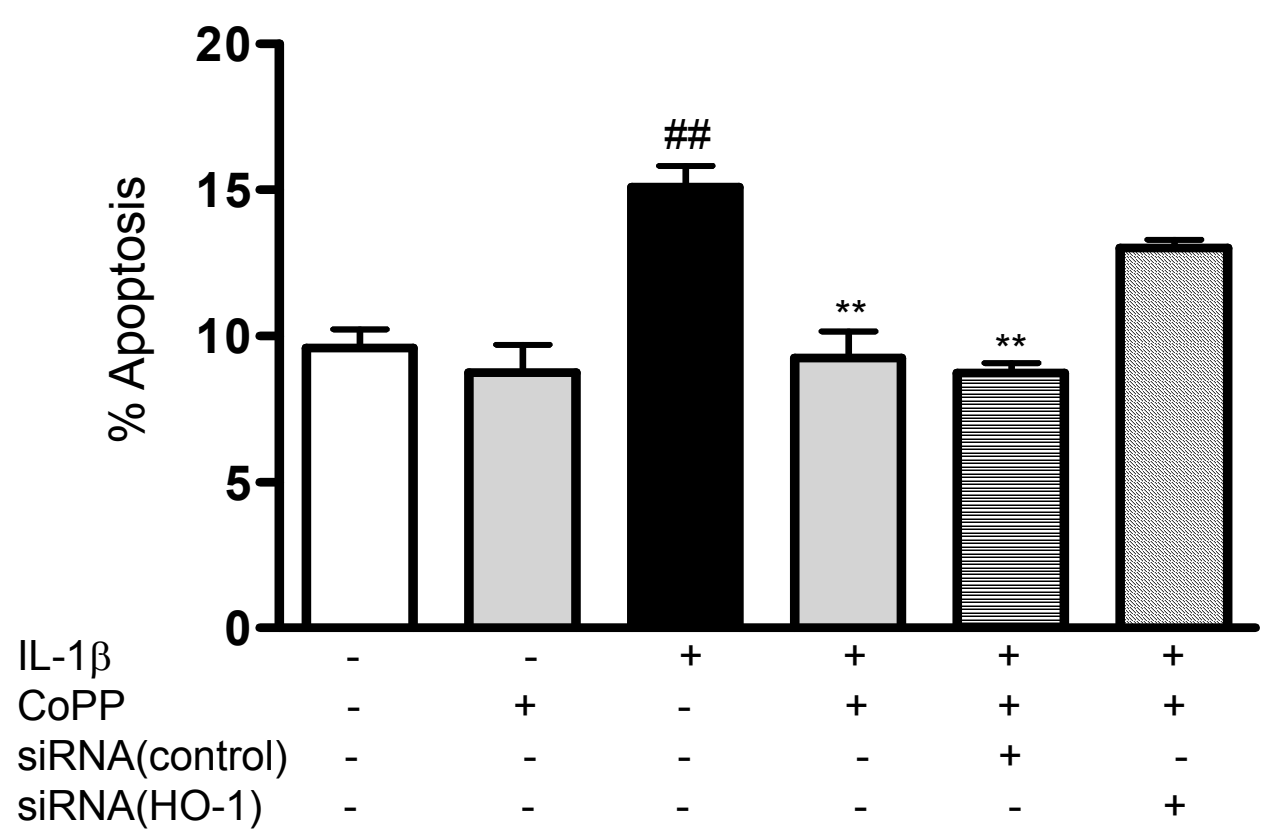


C
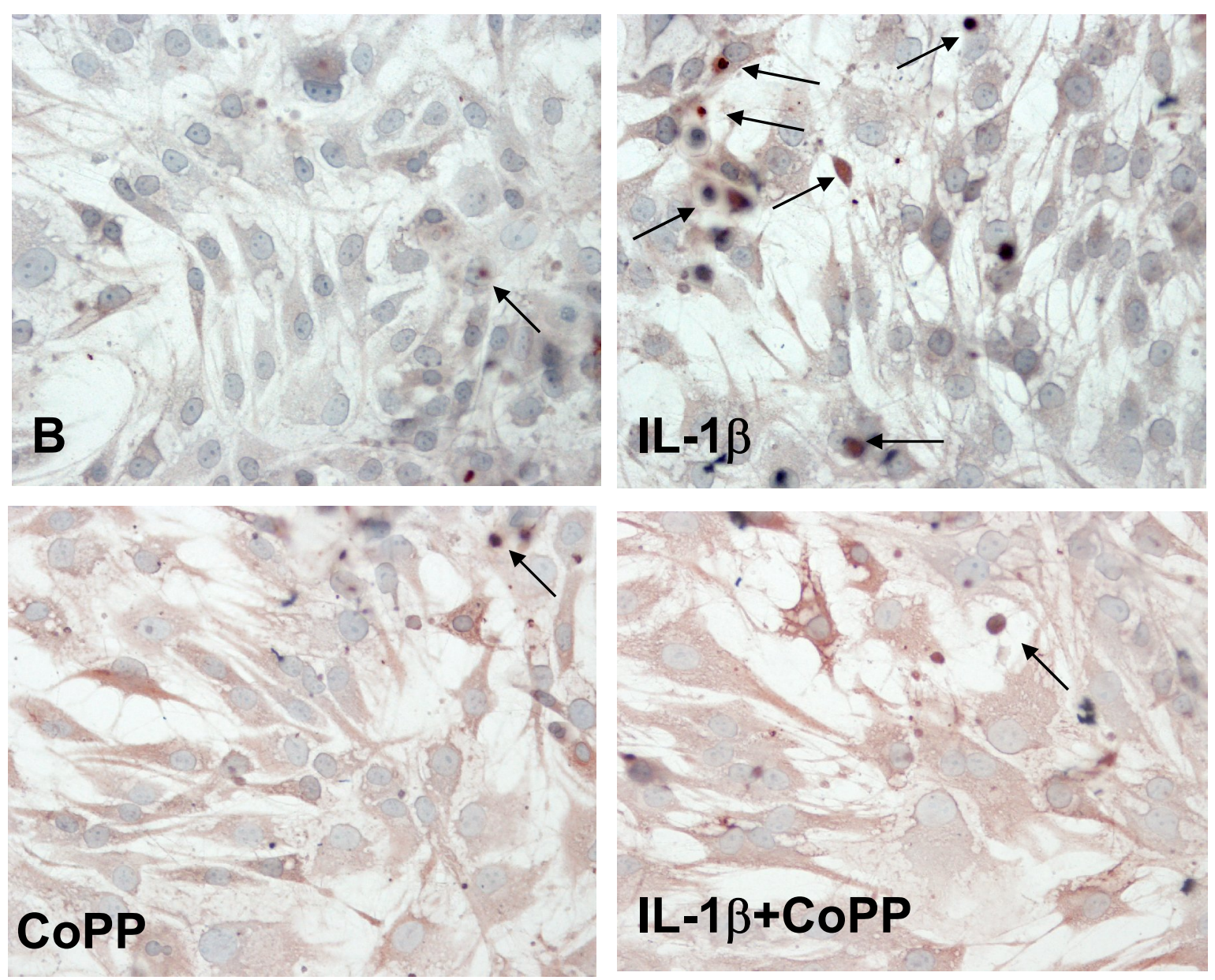


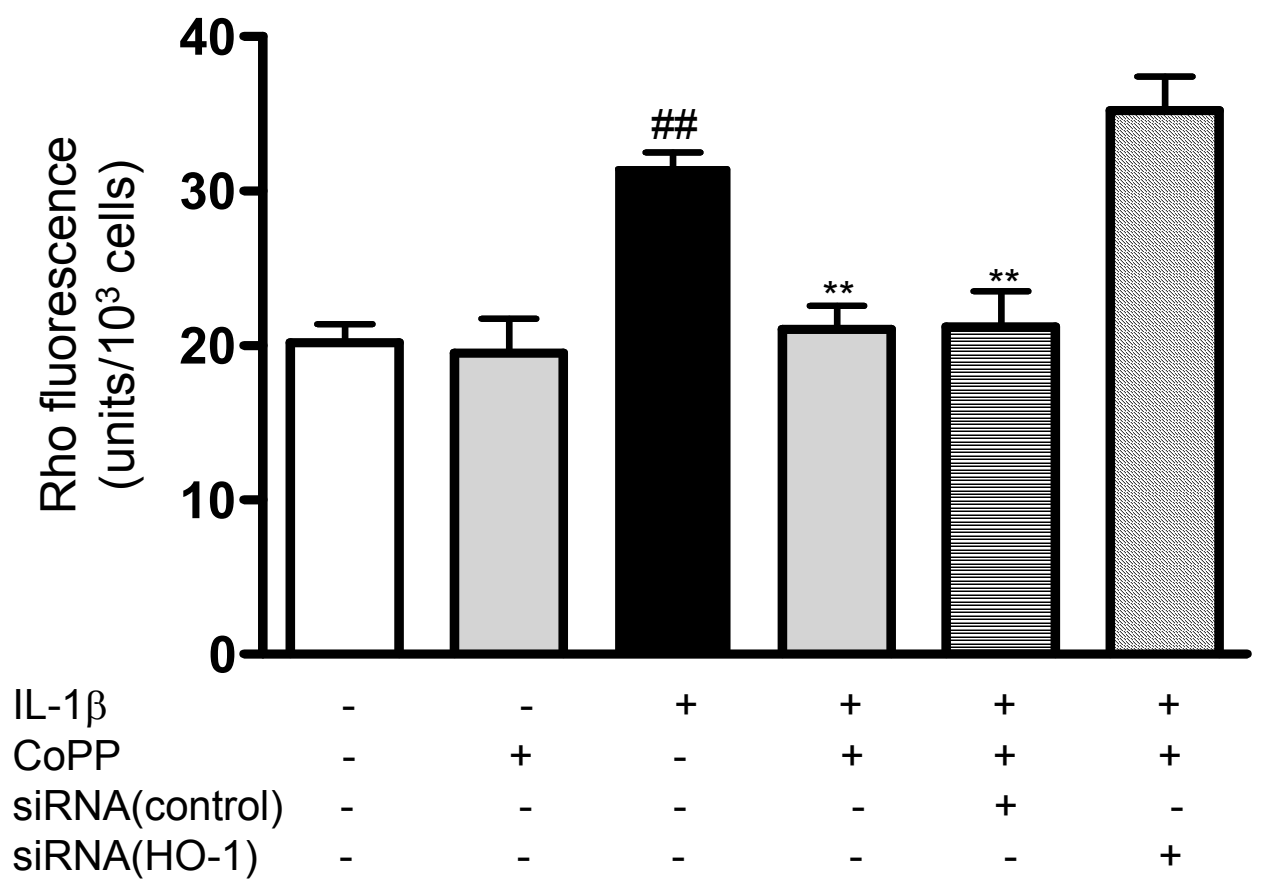


A

IL-1 $\beta$

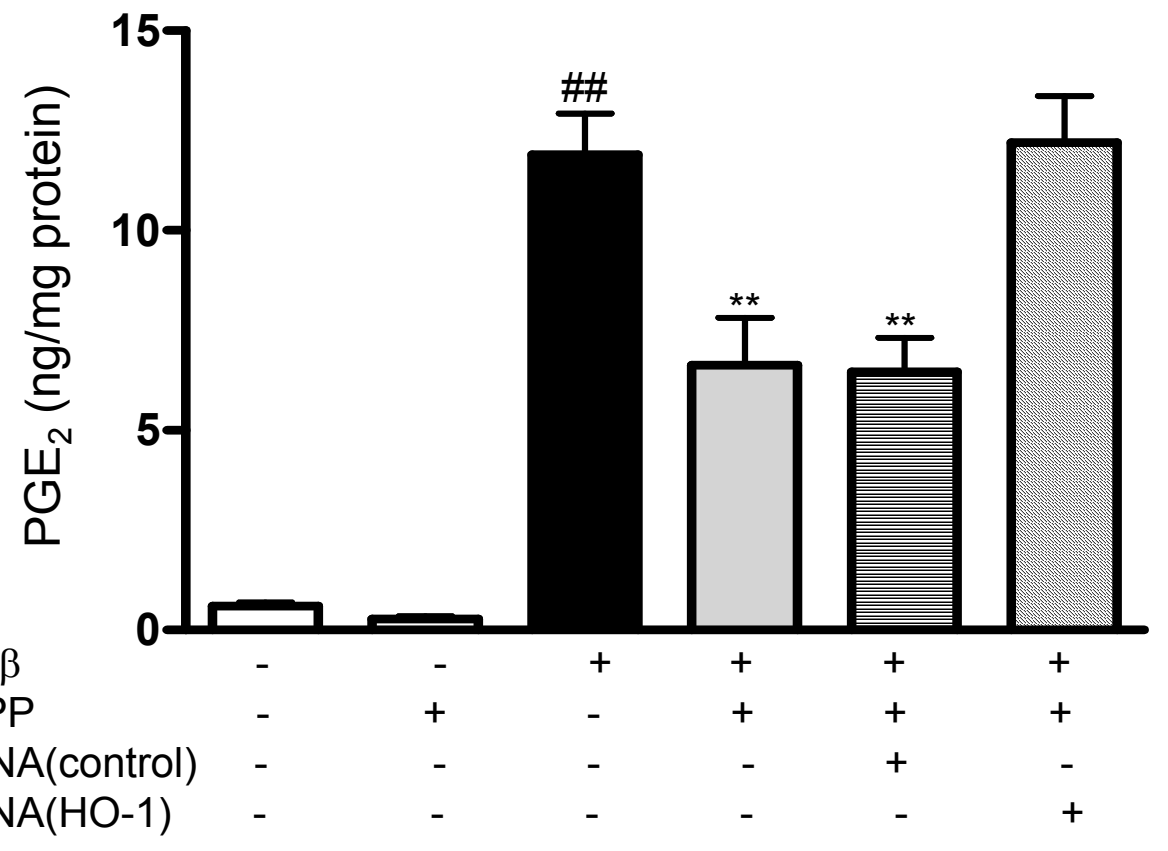

B

HO-1

coX-2

MPGES-1

$\beta$-Actin

IL-1 $\beta$

CoPP

siRNA(control)

siRNA(HO-1) 


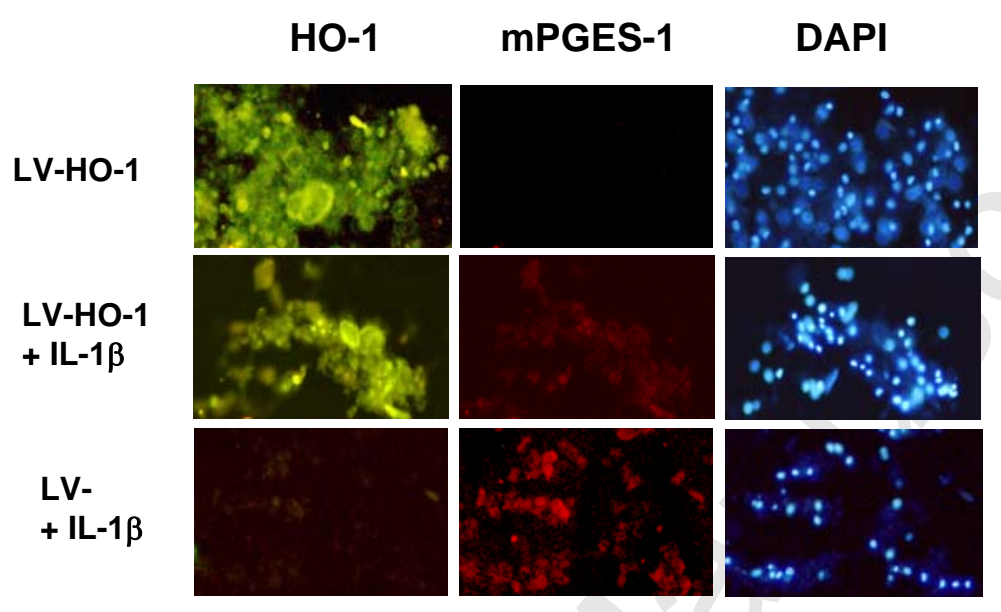


A

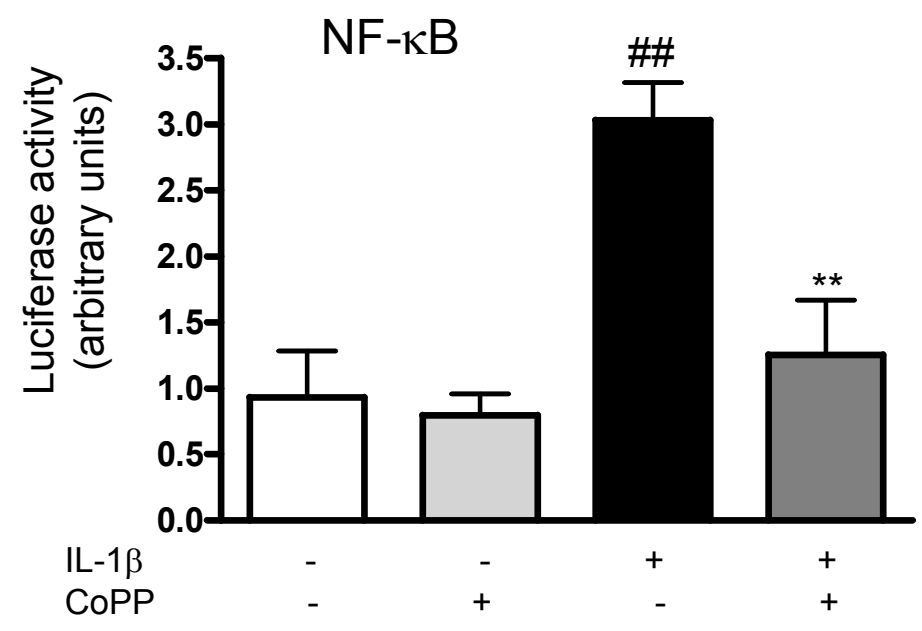

B

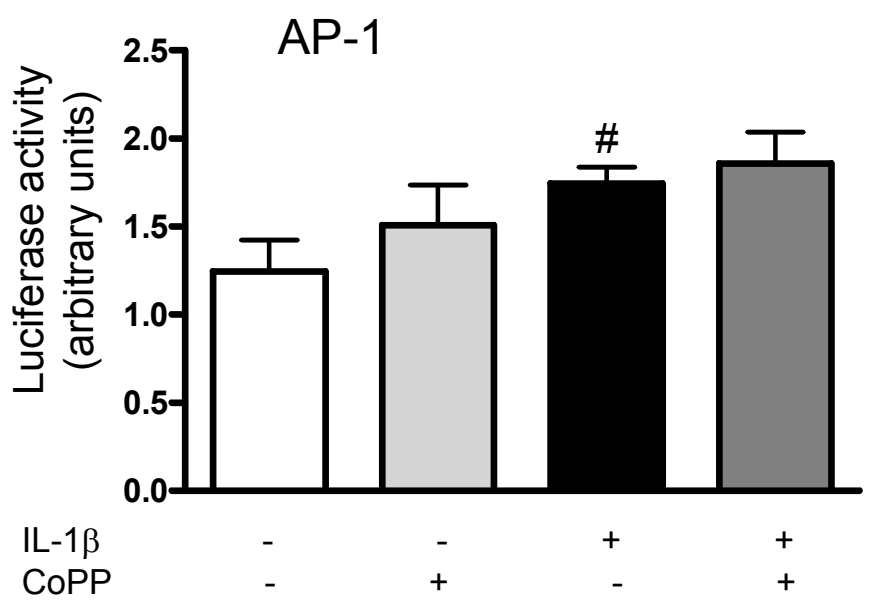

C

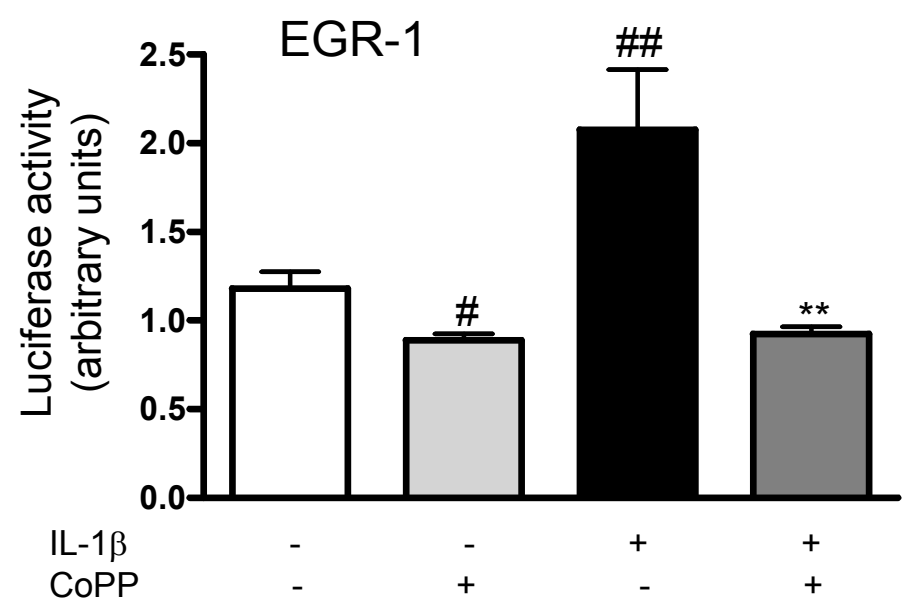


$1 \mathrm{C}$

C
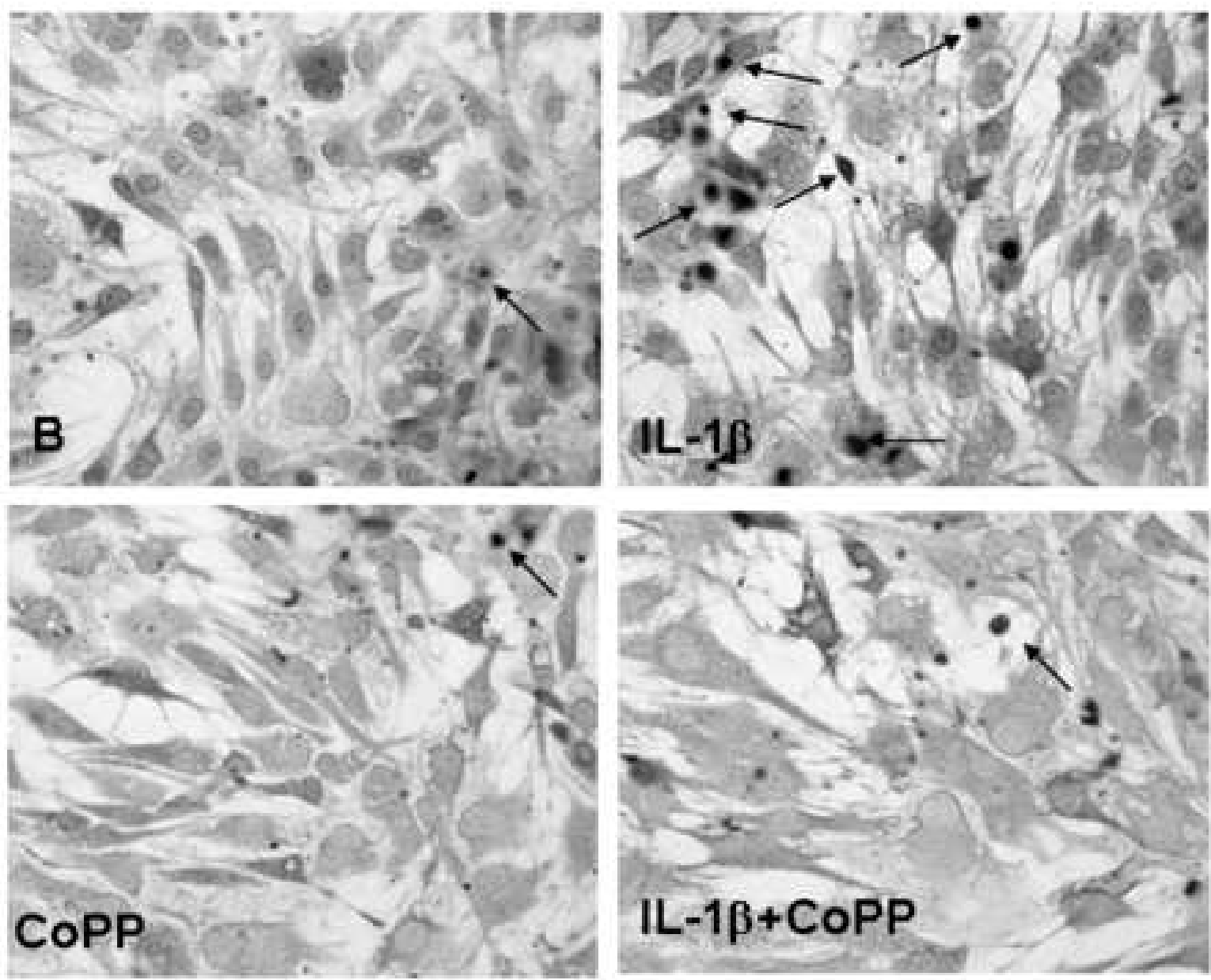


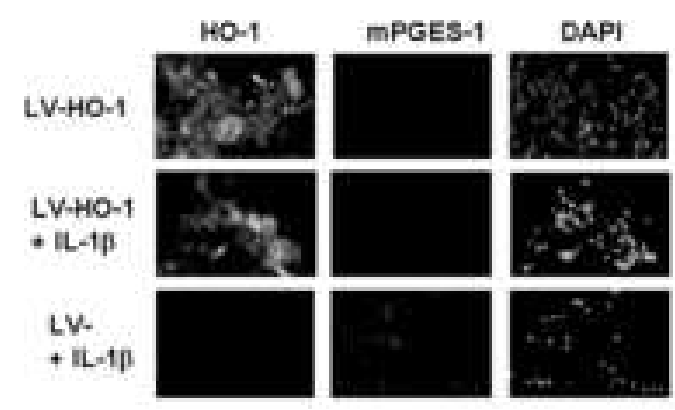

rage 38 of 38 